\title{
Research on the Influence of Values of Tibetan College Students from the Perspective of New Media
}

\author{
Rongshan WANG \\ Applied Psychology Department of Northwest University for Nationalities, Lanzhou, China
}

\begin{abstract}
Aims: to explore the influence of values of Tibetan College Students by the spread of new media. Methods: "questionnaire of College Students' Internet using ", "questionnaire of vocational values " and "questionnaire of life values " were used to survey and analysis the influence of the new network media to the values of the Tibetan students, including life values and vocational values. Results: research data shows that the new network media is increasingly becoming the essential information channel and exchange platform of Tibetan students, life values of the Tibetan college students tend to be positive, vocational values tend to be more diversified.
\end{abstract}

KEYWORD: new media; Tibetan college students; values

\section{INTRODUCTION}

Distinguished from the traditional media, new media provide information services to the audiences depending on technology of digital, Internet and mobile communication. The unique mode of transmission and the unique function attract students groups and influence their way of thinking, thereby affecting the construction of life values and vocational values of college students. Life values is how to judge, how to create the value of life and basic views and the fundamental point of view. Vocational values includes development factors, health factors and the reputation factors.

\section{METHODS}

\subsection{The subjects}

Tibetan college students 360 people, 350 valid questionnaires were collected, questionnaire recovery rate was $97.2 \%$; of which 182 were men, accounted for $52 \%$, the female is 168 people, accounting for $48 \%$.There are 82 students in grade one, accounting for $23.4 \%$, there are 86 students in grade two, accounted for $24.6 \%$, there are 93 students in grade three, accounted for $26.6 \%$, there are 89 students in grade four, accounting for $25.4 \%$.

\subsection{Research tools}

"questionnaire of College Students Internet using " includes four dimensions: the degree of involvement network, the motivation of using network, the focusing content and attitude to network. "questionnaire of life values " tests from $\mathrm{Hu}$ Haiqing, "questionnaire of vocational values " tests from Ling Wenquan. The questionnaires are compiled according to the situation of local, all have high reliability and validity. Data statistics and analysis are made by SPSS17.0 software.

\section{RESULTS AND ANALYSIS}

\subsection{New network media has become the extremely important channels of information and communication platform of Tibetan students.}

According to the analysis of the research data

(1) the degree of involvement network: the net age of Tibetan students in 3-5 years accounted for $44.1 \%$, in $5-8$ accounted for $38.9 \%$; the daily average time of online from 2 to 4 hours accounted for $29.3 \%$, from 4 to 6 hours accounted for $29.9 \%$.

(2) the basic attitude to the network and the motivation of using network : $55.9 \%$ of Tibetan students think the network provide information timely and importantly.

(3) the concerned content of network: the main purpose of the $26.2 \%$ of the Tibetan students is the to chat with friends on the Internet, $33.6 \%$ is animation, film and music downloads, $40.2 \%$ is access to information, browse information etc.. 


\subsection{Life values of the Tibetan college students showed a tendency to be positive}

The 350 effective questionnaires of Tibetan students show that 297 people tend to positive values of life, accounting for $84.9 \%$, mainly into two categories: cherish life and enterprising life values.

Table 1 Effect to life values by degree of involvement and attitude towards the web

\begin{tabular}{|c|c|c|c|c|}
\hline & \multicolumn{2}{|c|}{ involvement degree on Network } & \multicolumn{2}{c|}{ attitude towards the Network } \\
\hline life values & $1-3$ hours of online time & $4-6$ hours of online time & timely and important & for his help \\
\hline positive life values & $80.90 \%$ & $78.60 \%$ & $79 \%$ & $82.90 \%$ \\
\hline Negative life values & $19.10 \%$ & $21.40 \%$ & $21.00 \%$ & $17.10 \%$ \\
\hline
\end{tabular}

The degree of involvement and attitude towards the web do not exist significant difference. The research data showed positive life values.

Strong demand for network information presented positive tendency life values. Strong demand for network relax presented negative tendency life values. Most of the demand of Tibetan students presented positive life values.

Table 2 Effect to life values by motivation and focusing contents

\begin{tabular}{|c|c|c|c|c|c|}
\hline life values & chat & cartoon movie & data & news & space \\
\hline positive life values & $71.20 \%$ & $57.80 \%$ & $90.10 \%$ & $50.70 \%$ & $88.30 \%$ \\
\hline negative life values & $28.80 \%$ & $42.50 \%$ & $9.90 \%$ & $49.30 \%$ & $11.70 \%$ \\
\hline
\end{tabular}

\subsection{Vocational values of Tibetan college students presents the diversification}

Abundant information of New media technology will enable students to understand the employment needs of the industry in a timely manner. Tibetan College Students' Vocational value distribution presents the diversification. Development factors, health factors and reputation factor are all considered. The data show that $53 \%$ of people consider firstly is development factors; $25 \%$ of the people prefer health factors; $22 \%$ of the people consider the reputation factors.

The more deeply involved in the network, the more diversified the vocational values are. As shown in Table3, the development factors is firstly considered, then the health factors, the reputation factors is then followed.

Table 3 Effect to Vocational values by degree of involvement and attitude to network

\begin{tabular}{|c|c|c|c|c|}
\hline & \multicolumn{2}{|c|}{ involvement degree on Network } & \multicolumn{2}{c|}{ attitude towards the Network } \\
\hline Vocational values & net age 3-5 years & $4-6$ hours daily & timely and important & useful to employment \\
\hline Development factors & $40.90 \%$ & $39.80 \%$ & $53 \%$ & $39.40 \%$ \\
\hline Health factors & $32.70 \%$ & $33.20 \%$ & $46.80 \%$ & $34.60 \%$ \\
\hline Reputation factors & $26.40 \%$ & $27.00 \%$ & $38.70 \%$ & $26 \%$ \\
\hline
\end{tabular}

\section{CONCLUSION}

With the development of Internet and mobile phone as the material basis of the network, values' media environment has changed completely. The Tibetan college students' values change and improve with the spread of new media information. Research data shows that the new network media is increasingly becoming the essential information channel and exchange platform of Tibetan students, life values of the Tibetan college students tend to be positive, vocational values tend to be more diversified. Development factors, health factors and reputation factor are all considered. the primary consideration is development factors, then the health factors, finally followed by reputation factors.

\section{ACKNOWLEDGEMENTS}

Fund project: Young fund project of the ministry of education(2012): the development of the ethnic attitude and its influencing factors (12yjc190025); In 2012, the central University basic scientific research fund project: Research on the new media influence on Tibetan college students' vocational values and life values (zyz2012043) 


\section{REFERENCES}

[1] Qian Wenbin. 2010. The influence of new media on college students value orientation and countermeasures. The press, (3).
[2] Ling Wenquan, \&Party Liluo. 1999.Study of college students in our country occupation value view. Journal of psychology, 31 (3): 342-348.

[3] Jin Shenghua, \&Li Xue. 2005. The occupational values of college students: means and purpose. Psychological Bulletin, 37 (5): 650-657. 